\title{
The effect of a phosphonate-based antiscalant on the morphology and precipitation kinetics of gypsum: The Red Sea - Dead Sea project
}

\author{
Amit G Reiss ${ }^{1, * 2}$, Jiwchar Ganor ${ }^{1}$, and Ittai Gavrieli ${ }^{2}$ \\ ${ }^{1}$ Ben-Gurion University of the Negev. Department of Geological and environmental sciences, P.O.B 653 \\ Beer-Sheva, Israel \\ ${ }^{2}$ Geological survey of Israel, 32 Yeshayahu Leibowitz Street Jerusalem, Israel
}

\begin{abstract}
The proposed plan for the 'Red Sea - Dead Sea project' has raised concerns that the surface water of the Dead Sea would turn white due to gypsum precipitation. The occurrence of such an event would depend on the precipitation kinetics and the morphology of the precipitating crystals. Batch experiments were conducted to study the effect of a phosphonate-based antiscalant on the precipitation kinetics and morphology of gypsum under the conditions of this project.

Addition of the antiscalant was found to increase the induction time by a factor of 1.2-5 over the entire range of Dead Sea - Seawater mixtures investigated, depending on brine composition. Once nucleation occurred, the antiscalant also slowed the crystal growth by a factor of 1.2-3. However, when the solutions were seeded with gypsum, the rate of crystal growth with and without antiscalant were similar, within uncertainty. More crystals precipitated from unseeded solutions with no antiscalant and the crystals were smaller and less tabular than those precipitated from unseeded solutions with antiscalant.
\end{abstract}

\section{Case Study}

Water demand is a limiting factor for the development, or even for life, in arid regions. Thus, overcoming water stress can be the difference between conflict or peaceful collaboration. A contemporary example is the 'Red Sea - Dead Sea project' (RSDSP), agreed upon by the governments of Israel and the Hashemite Kingdom of Jordan. The scheme of the project is to desalinate seawater (SW) by reverse osmosis along the shore of the Gulf of Eilat, producing potable water for both parties, and conveying the reject brine (RB) to the Dead Sea (DS) to slow down the rate of its water level decline. A pilot project is currently being discussed between the nations, which in its first phase is expected to convey to the DS a mixture of RB, and SW (i.e. diluted RB- DRB) with a composition that is expected to be that of the SW concentrated by a factor of 1.27. Scaling on the reverse osmosis membranes during desalination limits

* Corresponding author: reissam@post.bgu.ac.il 
desalination yield and may cause a price increase. It has thus become a common practice to add anti scaling agents to the SW before their desalination [1]. These antiscalants remain in the RB and in the case of the RSDSP would be discharged into the DS as part of the DRB.

The DS is a hyper-saline lake $(\sim 350 \mathrm{~g} / \mathrm{l})$ which is over saturated with respect to gypsum. The degree of saturation, $\Omega_{\text {gypsum }}$, is defined as: $\left(a_{\mathrm{Ca}^{2+}} * a_{\mathrm{SO}_{4}^{2-}} * a_{\mathrm{H}_{2} \mathrm{O}^{2}}\right) /\left(a_{\mathrm{Ca}^{2+}} * a_{\mathrm{SO}_{4}^{2-}} * a_{\mathrm{H}_{2} \mathrm{O}^{2}}\right)_{\mathrm{eq}}$, where $a_{i}$ is the activity of the $\mathrm{i}^{\text {th }}$ species. Currently $\Omega_{\text {gypsum }}$ in the lake is 1.34 , yet, due to kinetic reasons the DS remains oversaturated. The slow kinetics and low precipitation potential of the mineral in DS brine result in negligible amounts of the mineral being precipitated in the lake. However, experimental work and thermodynamic calculations have shown that mixing between the calcium rich-DS and sulfate rich-SW or RB would lead to an increase in $\Omega_{\text {gypsum }}$ and gypsum precipitation potential, resulting in an increase in the precipitation rate of gypsum [2-4]. It is thus expected that due to the RSDSP, gypsum precipitation in the lake would become much more significant. A major environmental concern, yet to be resolved, regards the fate of the gypsum. If massive nucleation and growth of minute gypsum crystals will occur, the forming crystals will likely stay afloat, thereby "whitening" the surface water and changing the general appearance of the DS. Whether whitening of the surface water will take place depends much on the ratio of the rates of nucleation to crystal growth, which would determine the number and size of gypsum crystals, and on the morphology of the precipitated crystals. The antiscalants which would be introduced to the DS during the RSDSP are likely to affect both the kinetics of gypsum precipitation and the morphology of the crystals. Hence, the present study focuses on the effect that a phosphonate-based antiscalant (Osmotech 1070), similar to the one that is expected to be used during the RSDSP, has on gypsum precipitation kinetics and morphology in DS-SW and DS-DRB mixtures.

\section{Methods}

Seawater and RB containing the phosphonate-based Osmotech 1070 antiscalant were collected at the Soreq desalination plant on the Mediterranean coast of Israel. The RB and SW collected were mixed to create a brine with a chemical composition that is similar to that which is expected to be dumped into the DS during the RSDSP pilot (i.e., concentrated by a factor of 1.27 compared to SW). In addition, SW was evaporated in order to create evaporated seawater (ESW) with a composition similar to that of the DRB but with no antiscalant. The final solutions used in the experiments were created by mixing DS brine with variable amounts of either DRB, ESW or RB.

Two sets of batch experiments were conducted: a set with gypsum seeds and a set of unseeded experiments. Each set consisted of several experiments in which the weight percent (\%wt) of DS ranged from $55-90 \%$. In the seeded experiments $\sim 0.5 \mathrm{~g}$ of gypsum powder (53$150 \mu \mathrm{m})$ was added to the solutions. The solutions were kept in a thermostatic shaking bath set to $25.0 \pm 0.1{ }^{\circ} \mathrm{C}$. At designated times, a sample was taken from each solution, and its $\mathrm{SO}_{4}{ }^{2-}$ concentration was measured using an ion chromatograph. The $\mathrm{pH}$ of the solutions was measured at the end of the experiments and the crystals from the unseeded experiments were separated from solution, rinsed with ethanol to avoid further precipitation and imaged with a binocular.

\section{Results and discussion}

The time that elapses between the development of over saturation and the detection of a new phase in solutions containing no seeds is known as the 'induction time' $\left(\mathrm{T}_{\text {ind }}\right)$. This time is 
inversely proportional to the rate of nucleation [5]. In the present research, the induction time was defined as the time required for a detectable change in the measured $\mathrm{SO}_{4}{ }^{2-}(\geq 3 \%)$.

An inverse relationship between $T_{\text {ind }}$ and $\Omega_{\text {gypsum }}$ was found in DS-SW mixtures. Such a relationship was already described by Reznik et al [4]. This relationship is enhanced when an antiscalant is added (Fig 1). The inhibiting effect of the antiscalant on nucleation for a specific solution composition was defined by the factor in which $T_{\text {ind }}$ for a $\mathrm{DS}+\mathrm{DRB}$ solution is retarded compared to $T_{\text {ind }}$ of the similar DS + ESW solution (Retardation Factor $(R F)=T_{\text {ind }}(D S$ $+\mathrm{DRB}) / \mathrm{T}_{\text {ind }}(\mathrm{DS}+\mathrm{ESW})$. The inhibition of nucleation based on RF can be divided into three groups: RF of 1.2 for solution containing $90 \%$ wt DS $+10 \%$ wt DRB, $\sim 1.7$ for the range of 60 $85 \%$ DS with the remaining of the solution being DRB and $>5$ for $55 \%$ DS $+45 \%$ DRB. The increase in RF with the relative amount of DRB (i.e., lower \%wt DS) is probably due to the higher concentration of the antiscalant in these solutions, which correspond to the increase in the percentage of the DRB that contain the antiscalant.

The phosphonate species active in scale inhibition are both the fully dissociated $\left(\mathrm{PO}_{3}{ }^{2-}\right)$ and the protonated $\left(\mathrm{PO}_{3} \mathrm{H}^{-}\right)$species. The former penetrates the hydration layer surrounding the gypsum while the latter adsorbs more effectively to the reactive sites on the surface of the mineral [6]. The speciation of the phosphonate group is $\mathrm{pH}$ dependent. This results in maximum efficiency at circumneutral $\mathrm{pH}$ and with diminishing efficiency as $\mathrm{pH}$ decreases [7]. The $\mathrm{pH}$ of the Dead Sea is $\sim 6.2$ whereas that of seawater is $\sim 8$. Consequently, solutions with different mixing ratios of DS \& DRB would not only have different antiscalant concentration but also different $\mathrm{pH}$ values. Thus, solutions with a high fraction of DS would have low concentration of total antiscalant and lower $\mathrm{pH}$ which would result in a lowered RF. In contrast, solutions with lower \%wt DS would have higher total antiscalant and $\mathrm{pH}$ that is closer to neutral and therefore an increased RF. Substitution of the fraction of DRB in solution by RB would result in an increase in both $\Omega_{\text {gypsum }}$ and the concentration of the antiscalant. Such solutions were found to have shorter $\mathrm{T}_{\text {ind }}$ as compared to the corresponding DS-DRB mixtures with the mixing ratios. This implies that despite the increased content of the antiscalant $T_{\text {ind }}$ is more strongly dependent on $\Omega_{\text {gypsum }}$ than on the concentration of antiscalant. The result is 'flattening' of the curve when $\mathrm{T}_{\text {ind }}$ is plotted vs. \%wt DS (Fig. 1)
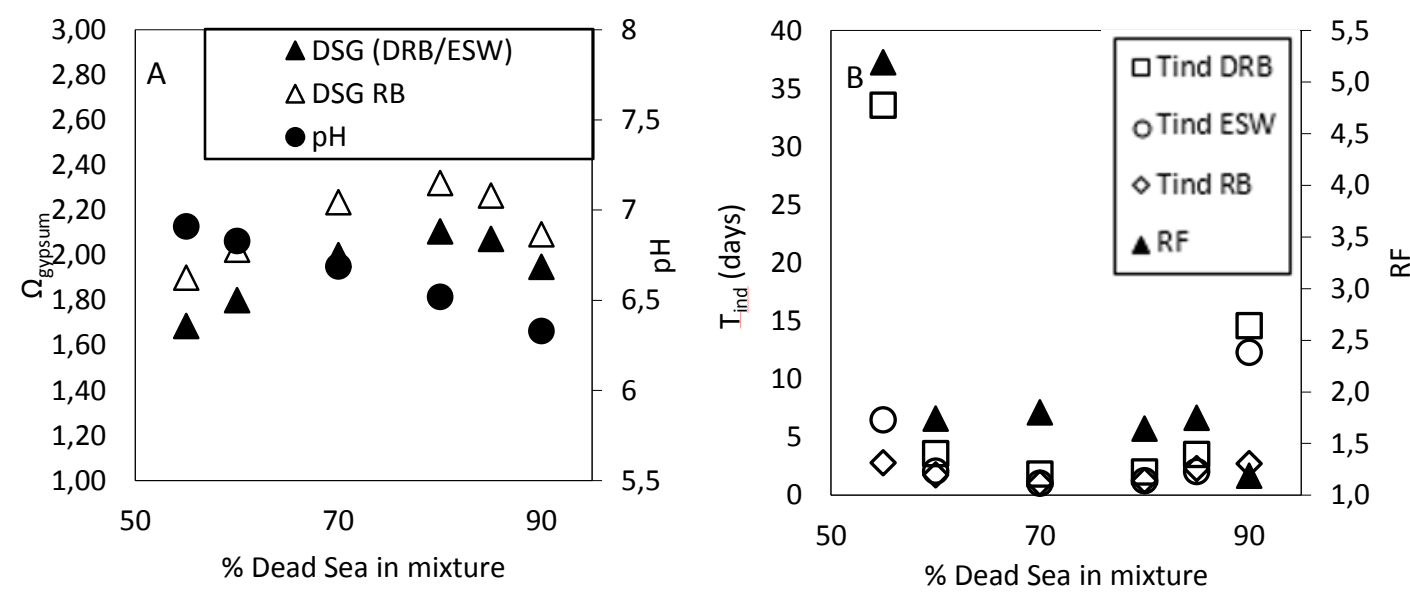

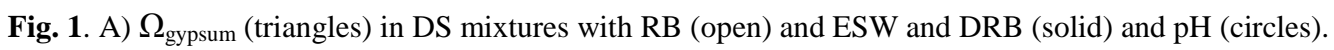
B) RF (triangle) and Tind for DS mixtures with DRB (square), ESW (circle) and RB (diamond) experiments.

It has been previously shown [8] that the morphology of gypsum precipitated from DS-SW mixtures is composition-dependent, with crystal populations becoming increasingly elongated (i.e., becoming more needle-like) when the fraction of SW in the mixture is increased. The 
crystals precipitated in the current experiments are in agreement with these results (Fig 2). In the present study we show that the addition of the antiscalant also affects the crystals. Crystals precipitated from similar compositions become larger and more tabular (i.e., crystals have a shorter length to width ratio) when precipitated from solutions containing the antiscalant. In addition, fewer crystals precipitate in the presence of the antiscalant. This effect is increased with an increase in RF. In solutions containing 55\% DS crystal habit and size is distinctly different when the complementary $45 \%$ is DRB or ESW, with crystals precipitated from the DS-DRB mixture being more tabular and larger. However, when the component of DS is increased to $90 \%$ there is no clear difference in habit between crystals precipitated from DSESW mixtures and those precipitated from DS-DRB mixtures (Fig 2). Alteration of gypsum morphology is dependent on the concentration of the additives that alter its morphology [9]. Furthermore, antiscalant reduces the number of crystals that develop [10]. For a specific composition, a mixture of DS with either DRB or ESW has the same precipitation potential. As $\mathrm{RF}$ is increased, the total amount of precipitate is distributed onto relatively fewer crystals. This together with the increased antiscalant concentration causes the reduction in the number of crystals while they become larger and more tabular.
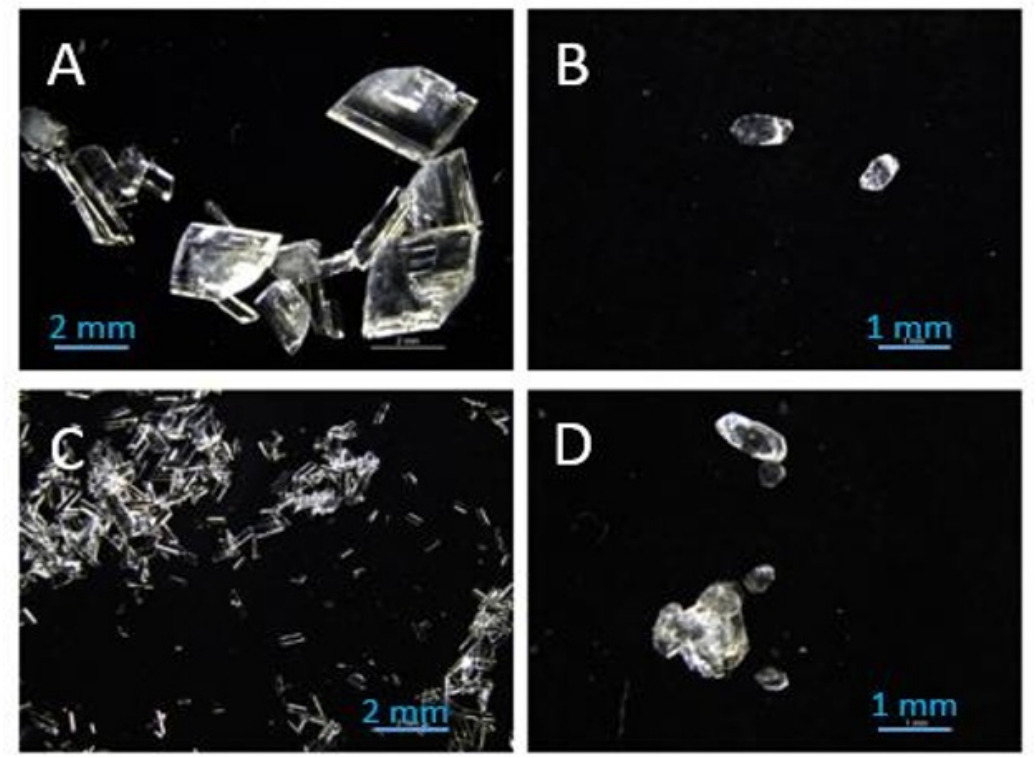

Fig. 2. Gypsum crystals precipitated from solutions of A) $55 \%$ DS + 45\% DRB, B) $90 \%$ DS +10\% DRB, C) $55 \% \mathrm{DS}+45 \% \mathrm{ESW}$ and D) $90 \% \mathrm{DS}+10 \% \mathrm{ESW}$. Note that there are fewer crystals that become larger and more tabular in the solutions containing 55\% DS when antiscalant is added.

Figure 3 presents the change of $\mathrm{SO}_{4}{ }^{2-}$ concentration with time in both seeded and unseeded experiments. In all of the unseeded experiments once gypsum precipitation was determined,

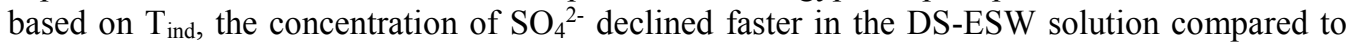
the DS-DRB solution of similar composition. The difference in rate $[\mathrm{mol} / \mathrm{kg} / \mathrm{day}]$ between the DS - DRB or ESW were increased as the \% DS in the solution decreased from a factor of 1.14 to a factor of $3(90 \%$ and $55 \%$ DS respectively). Phosphonate antiscalants inhibit precipitation by adsorbing onto the mineral surfaces [10]. Different crystal faces of a mineral have different surface properties such as density of reactive sites. A change in crystal morphology, as is seen in the various DS - ESW mixtures can therefore alter the ability of an antiscalant to adsorb onto the mineral. This needs to be considered along with the change in solution composition and properties of the antiscalant when assessing the fate of gypsum in the DS. However, in seeded experiments the changes of $\mathrm{SO}_{4}{ }^{2-}$ in time were independent of the presence of the antiscalant 
(Fig 3). This trend was found in all seeded experiments. Thus, regardless of the composition of the solution the ability or lack of it of the antiscalant to inhibit crystal growth is a function of the surface area available for growth.

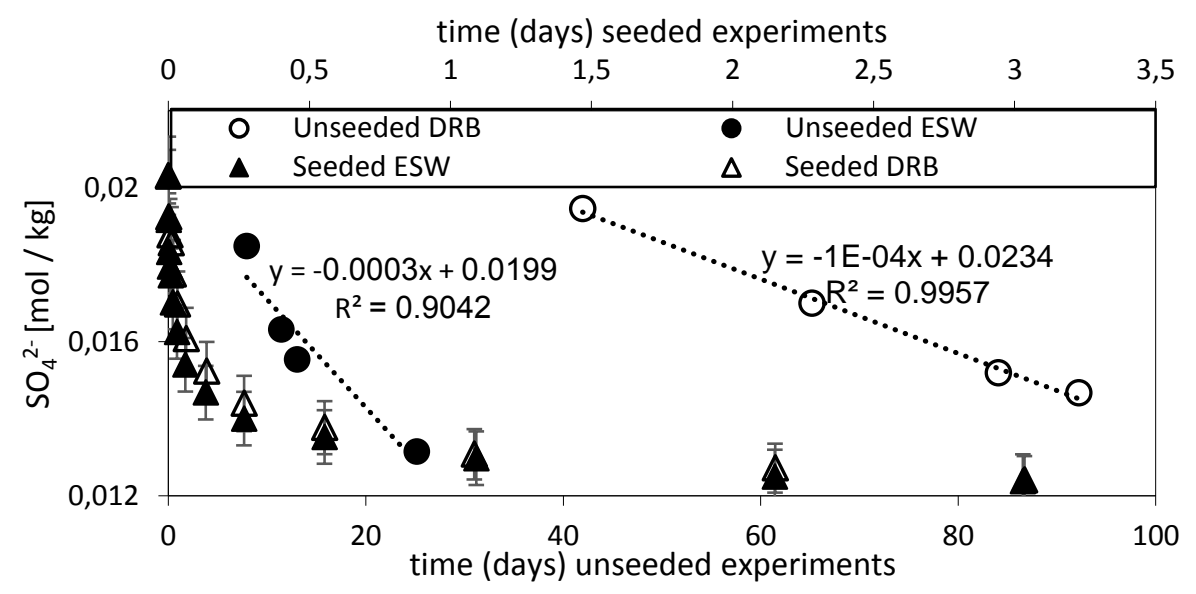

Fig. 3. Change in $\mathrm{SO}_{4}{ }^{2-}$ concentration with time in experiments in which $55 \%$ DS was mixed with $45 \%$ SWE (Solid) and DRB (open). Circles are unseeded experiments and triangles are seeded experiments. Slopes of the plots for the unseeded experiments represent the precipitation rate of gypsum ( $\mathrm{mol} / \mathrm{kg} / \mathrm{day})$.

The annual volume of DRB which is proposed to be dumped into the lake during the pilot is of the same order of magnitude as the volume of the Lisan Bay $\left(\sim 400^{*} 10^{6} \mathrm{~m}^{3}\right)$ on the south eastern shore, into which it is going to be discharged. Depending on the rate of exchange of the water in the bay, it is possible that the composition of the water there, at least for a certain time period, would be within the range covered by the experiments performed in this study. Eventually the composition in the bay would be determined by the discharge rate of DRB into the bay, the rate in which the two end members mix and the dynamics of flow between the bay and the lake at large. The range of $\mathrm{T}_{\mathrm{ind}}$, antiscalant efficiencies and crystal morphologies found here thus demand further research on the dynamics of the lake if an accurate prediction as to precipitation kinetics and morphology is to be provided.

\section{References}

1. M. Gleode, T. Melin, Desalination., 224, 71-75 (2008)

2. I.J. Reznik, J. Ganor, A. Gal, I. Gavrieli, Environ. Chem., 6, 416-423 (2009)

3. I.J. Reznik, I. Gavrieli, G. Antler, J, Ganor, Geochim. Chosmochim. Acta, 75, 2187-2199 (2011)

4. I.J. Reznik, J. Ganor, C. Gruber, I. Gavrieli, Geochim. Chosmochim. Acta, 85, 75-87 (2012)

5. O. Sohnel, J.W. Mullin, J. Colloid Interface Sci., 123, 43-50 (1988)

6. M.P.C Weijnen, G.M. Van Rosmalen. J. Cryst. Growth., 79, 157-168 (1986)

7. Y.O. Rosenberg, I.J. Reznik, S. Zmorah-Nahum, J. Ganor, Desalination, 284, 207-220 (2012)

8. A.G. Reiss, I. Gavrieli, J. Ganor, Procedia Earth Planet. Sci., 17, 376-379 (2017)

9. D. Montagnino, E. Costa, F.R. Massaro, G. Artioli, D. Aquilano, Cryst. Res. Technol., 46, 1010-1018 (2010)

10. M. Gleode, T. Melin, Desalination, 199, 26-28 (2006) 